\title{
Heat shock protein 27 is associated with better nerve function and fewer signs of neuropathy
}

\author{
K. Pourhamidi • L. B. Dahlin • K. Boman • \\ O. Rolandsson
}

Received: 7 June 2011 / Accepted: 11 August 2011 / Published online: 10 September 2011

(C) Springer-Verlag 2011

\begin{abstract}
Aims/hypothesis High levels of serum heat shock protein 27 (sHSP27) have been associated with distal symmetric polyneuropathy in patients with type 1 diabetes. Our objective was to investigate the association between sHSP27, neuropathic signs and nerve function in individuals with normal glucose tolerance (NGT), impaired glucose tolerance (IGT) and type 2 diabetes.

Methods Participants were recruited consecutively from the population-based Västerbotten Intervention Program (NGT, $n=39$, IGT, $n=29$, and type 2 diabetes, $n=51$ ) and were matched for age and sex. sHSP27 levels were measured and nerve conduction studies were performed (peroneal and sural nerves). $z$ Scores for each nerve conduction measure were calculated and compiled into a composite $z$ score for the leg. Neuropathy disability score (NDS) was used to assess neuropathic signs.

Results Patients with diabetes had significantly lower sHSP27 levels (geometric mean sHSP27 206 pg/ml, 95\% CI 142, 299) than those with IGT (geometric mean sHSP27 $455 \mathrm{pg} / \mathrm{ml}, 95 \%$ CI 319, 650, $p<0.05)$ and controls (geometric mean sHSP27 $361 \mathrm{pg} / \mathrm{ml}, 95 \%$ CI 282, 461,
\end{abstract}

K. Pourhamidi $(\bowtie) \cdot$ O. Rolandsson

Department of Public Health and Clinical Medicine,

Family Medicine, Umeå University,

90185 Umeå, Sweden

e-mail: kaveh.pourhamidi@fammed.umu.se

L. B. Dahlin

Department of Clinical Sciences Malmö, Hand Surgery,

Skåne University Hospital, Lund University,

Malmö, Sweden

K. Boman

Department of Public Health and Clinical Medicine, Medicine,

Skellefteå Hospital, Umeå University,

Umeå, Sweden $p<0.05$ ). Participants with few signs of neuropathy (first tertile, NDS $\leq 2$ ) had significantly higher sHSP27 levels (geometric mean sHSP27 $401 \mathrm{pg} / \mathrm{ml}, 95 \%$ CI 310, 520) than participants with many signs (third tertile, NDS $\geq 7$ ) (geometric mean sHSP27 $192 \mathrm{pg} / \mathrm{ml}, 95 \% \mathrm{CI} 128,288, p=0.007)$. The highest sHSP27 tertile was associated with better nerve function, adjusted for age, sex, statin medication and $\mathrm{HbA}_{1 \mathrm{c}}$ (OR 2.51, 95\% CI 1.25, 5.05, $p<0.05$ ).

Conclusions/interpretation High sHSP27 levels were associated with better nerve function and fewer neuropathic signs in NGT, IGT and type 2 diabetes.

Keywords Complications · Diabetes mellitus $\cdot$ Heat shock protein $\cdot$ Metabolism $\cdot$ Neuropathy
Abbreviations
2hPG $2 \mathrm{~h}$ plasma glucose
CVD Cardiovascular disease
fPG Fasting plasma glucose
hsCRP High-sensitivity C-reactive protein
HSP27 Heat shock protein 27
IGT Impaired glucose tolerance
NDS Neuropathy disability score
NGT Normal glucose tolerance
sHSP27 Serum HSP27
VIP Västerbotten Intervention Program

\section{Introduction}

Heat shock protein 27 (HSP27) has been reported to be involved in survival of neurons $[1,2]$ and hereditary types of neuropathy [3]. Overproduction of HSP27 has been observed in some target tissues of diabetes complications [4-7], but not in all [8]. Proposed mechanisms mediating a 
neuroprotective effect include stabilisation of actin cytoskeleton [9] and inhibition of apoptosis [10].

High levels of serum HSP27 (sHSP27) have been associated with distal symmetric sensorimotor polyneuropathy in patients with type 1 diabetes [11]. Thus, it has been hypothesised that a reduced nerve function might be associated with increasing levels of sHSP27, and might be an indicator of neuropathy [11]. The association between nerve function and SHSP27 has not been studied in individuals with type 2 diabetes and impaired glucose tolerance (IGT).

Thus, our objective was to investigate the association between nerve function and signs of neuropathy and sHSP27 in individuals with different glycaemic status.

\section{Methods}

\section{Study population}

In this exploratory cross-sectional study we recruited participants with normal glucose tolerance (NGT) and IGT, and type 2 diabetes patients, aged $60 \pm 1$ years, from the populationbased Västerbotten Intervention Program (VIP) [12]. The NGT and IGT individuals performed two standardised OGTT after overnight fasting with about 1 week's interval to verify their glucose status. Both OGTT results should be within the cut-off values for fasting plasma glucose (fPG) and $2 \mathrm{~h}$ plasma glucose (2hPG) according to 1999 WHO recommendations (NGT: $\mathrm{fPG}<7.0 \mathrm{mmol} / 1$ and $2 \mathrm{hPG}<8.9 \mathrm{mmol} / \mathrm{l}$, IGT: fPG $<7.0 \mathrm{mmol} / 1$ and $2 \mathrm{hPG} \geq 8.9$ to $<12.2 \mathrm{mmol} / \mathrm{l}$ ) [13]. All individuals underwent a physical examination, by the same physician, including assessment of their medical history and medications. A history of peripheral artery disease, coronary artery disease or stroke was used to identify cardiovascular disease (CVD). Initially 129 individuals were recruited: four individuals withdrew, three individuals were excluded due to nutritional deficiencies (vitamin $\mathrm{B}_{12}$ and folate) and three were excluded due to neuropathy asymmetry caused by sciatica or stroke; this left 119 individuals in the study.

All individuals gave informed consent and the study was approved by the ethics committee of Umeå University, Umeå, Sweden.

\section{Measurements}

The participants' height, weight and blood pressure were measured and their BMI calculated $\left(\mathrm{kg} / \mathrm{m}^{2}\right)$. Blood samples were drawn and measured for $\mathrm{HbA}_{1 \mathrm{c}}$ (HPLC, TOSOH, Tokyo, Japan), high-sensitivity C-reactive protein (hsCRP) (Chemiluminescent Immunoassay System on Immulit, Siemens, Deerfield, IL, USA) and creatinine (Vitros 5.1 FS analyzer, Johnson\&Johnson, Raritan, NJ, USA). $\mathrm{HbA}_{1 \mathrm{c}}$ values were converted to the DCCT standard values using the formula: $\mathrm{HbA}_{1 \mathrm{c}}(\mathrm{DCCT})=0.923 \times \mathrm{HbA}_{1 \mathrm{c}}($ Mono $\mathrm{S})+$ 1.345 and are shown in both the DCCT (\%) and the International Federation of Clinical Chemistry and Laboratory Medicine (IFCC) ( $\mathrm{mmol} / \mathrm{mol})$ units. Conversion between DCCT and IFCC is by the following equation: $\mathrm{HbA}_{1 \mathrm{c}}(\mathrm{mmol} / \mathrm{mol})=\left[\mathrm{HbA}_{1 \mathrm{c}}(\%)-2.15\right] \times 10.929$. Serum HSP27 levels were measured by ELISA (Calbiochem, San Diego, CA, USA) and the calculated coefficient of variation for the analysis in our study was $10.6 \%$. In order to rule out other possible causes of neuropathy, e.g. thyroid disease, chronic alcoholism and nutritional deficiencies, blood samples were analysed for vitamin $\mathrm{B}_{12}$, folate, homocysteine, methylmalonic acid, thyroid stimulation hormone, thyroid hormones $T_{4}$ and $T_{3}, \gamma$-glutamyl transferase and carbohydrate deficient transferrin.

Neurophysiological assessment

Electrophysiology A neurophysiologist, who was blinded to the group identity of the individuals, performed the standardised motor and sensory nerve conduction studies. Measurements were performed on the right leg, including the conduction velocity of the peroneal and sural nerve and the amplitude of the sural nerve. A $z$ score for each nerve measurement was calculated using the formula: $z$ score $=$ individual value of participant-mean value of control group (NGT individuals) divided by SD of mean value for control group.

A composite $z$ score leg, reflecting the nerve function in the leg, was calculated: $(z$ score conduction velocity peroneal nerve $+z$ score conduction velocity sural nerve + $z$ score amplitude sural nerve) $/ 3$. The summation of nerve conduction attributes has been used elsewhere [14]. Tertiles of composite $z$ score leg were obtained for comparison.

Neuropathy disability score A modified version [15] of Dyck's original neuropathy disability score (NDS) [16] was used to evaluate signs of neuropathy in the lower extremities. The modified version of NDS included examination of sensory perception, reflexes and muscle strength, and has been used elsewhere [17]. Tertile score categories of NDS were formed for comparison.

Statistical analyses Data are presented as numbers ( $n$ ), proportions (\%) and distribution as mean and SD or median and interquartile range (IQR). For log-transformed data, geometric means with a $95 \%$ CI were used. Differences between groups were tested by ANOVA and subsequent Student's $t$ test for normally distributed variables. For nonnormally distributed variables, the Kruskal-Wallis test was applied with subsequent Mann-Whitney $U$ testing. Variables with non-normal distribution were also used after logarithmic transformation (sHSP27, creatinine, hsCRP, 
$\mathrm{HbA}_{1 \mathrm{c}}$ ). For log-transformed variables, differences between groups were tested with ANOVA and Dunnett's post hoc analysis and are presented as geometric means $(95 \% \mathrm{CI})$. Differences in proportions were tested using the $\chi^{2}$ test. Spearman's correlation coefficient was used in bivariate correlation analysis between independent variables. Univariate logistic regression analyses were performed for both composite $z$ score leg tertiles and sHSP27 tertiles as the dependent variable. In addition to age and sex, independent variables that were significantly associated $(p<0.05)$ with the dependent variables in the univariate analyses were used in the final multinomial logistic regression models (Table 3). When having composite $z$ score leg tertiles as the dependent variable against levels of sHSP27, the independent variables were entered in a forward stepwise manner in the following order: age, sex, height, weight and $\mathrm{HbA}_{1 \mathrm{c}}$. When having sHSP27 tertiles as the dependent variable against composite $z$ score leg values, the independent variables were entered in a forward stepwise manner in the following order: age, sex, statin medication, $\mathrm{HbA}_{1 \mathrm{c}}$. A $p$ value $<0.05$ was considered statistically significant. Statistical analyses were performed with SPSS 19.0 (SPSS Inc., Chicago, IL, USA).

\section{Results}

Baseline characteristics

As expected, those with diabetes had higher BMI and $\mathrm{HbA}_{1 \mathrm{c}}$ than those in the control and IGT groups (Table 1), but sHSP27 levels in the diabetes group were significantly lower than in the control and IGT groups (Table 1). We found no association between SHSP27 and CVD.

Spearman's rank correlation analysis revealed that sHSP27 was significantly and negatively correlated to $\mathrm{HbA}_{1 \mathrm{c}}$ $(r=-0.26)$, diabetes status $(r=-0.27)$ and NDS $(r=-0.30)$, but positively correlated to composite $z$ score leg $(r=0.23)$, amplitude of the sural nerve $(r=0.22)$ and conduction velocity of the peroneal nerve $(r=0.18$, all $p<0.05)$. The diabetes group had a significantly greater proportion of individuals with statin and renin-angiotensin system (RAS) inhibitor medication compared with controls (Table 1).

The conduction velocity of the peroneal nerve was significantly decreased in the IGT and diabetes groups compared with controls, and the conduction velocity of the sural nerve was significantly lower in the diabetes group than in controls (Table 1). The calculated composite $z$
Table 1 Clinical characteristics of the study population and results from nerve conduction studies and NDS by glucose status

Data are given as mean $\pm \mathrm{SD}$ or median (interquartile range Q1-Q3) and proportions (\%), or geometric means $(95 \% \mathrm{CI})$ for log-transformed data $\left(\mathrm{HbA}_{1 \mathrm{c}}\right.$, creatinine, hsCRP, sHSP27)

The score range for each NDS tertile is shown

$* p<0.05$ vs controls, ${ }^{\dagger} p<0.05$ vs IGT

\begin{tabular}{|c|c|c|c|}
\hline Variable & Controls & IGT & Type 2 diabetes \\
\hline$n$ (male/female) & $39(19 / 20)$ & $29(15 / 14)$ & $51(30 / 21)$ \\
\hline Age (years) & $61 \pm 0.6$ & $61 \pm 0.8$ & $61 \pm 1.3$ \\
\hline Duration of diabetes (years) & - & - & $7.2 \pm 0.9$ \\
\hline CVD, $n(\%)$ & $3(8)$ & $5(17)$ & $9(18)$ \\
\hline BMI $\left(\mathrm{kg} / \mathrm{m}^{2}\right)$ & $26.0 \pm 3.6$ & $26.9 \pm 5.4$ & $29.4 \pm 4.6^{*}$ \\
\hline $\mathrm{HbA}_{1 \mathrm{c}}(\%)$ & $5.4(5.3,5.4)$ & $5.5(5.4,5.6)$ & $7.3(7.0,7.7)^{* \uparrow}$ \\
\hline $\mathrm{HbA}_{1 \mathrm{c}}(\mathrm{mmol} / \mathrm{mol})$ & $36(34,36)$ & $37(36,38)$ & $56(53,61)^{* \dagger}$ \\
\hline Systolic blood pressure $(\mathrm{mmHg})$ & $128 \pm 17$ & $128 \pm 16$ & $131 \pm 14$ \\
\hline Diastolic blood pressure $(\mathrm{mmHg})$ & $76 \pm 7$ & $75 \pm 11$ & $76 \pm 7$ \\
\hline Creatinine $(\mu \mathrm{mol} / \mathrm{l})$ & $74(69,79)$ & $72(67,78)$ & $73(67,79)$ \\
\hline hsCRP (mg/l) & $0.99(0.71,1.38)$ & $1.15(0.81,1.65)$ & $1.54(1.14,2.09)$ \\
\hline sHSP27 (pg/ml) & $361(282,461)$ & $455(319,650)$ & $206(142,299)^{* \dagger}$ \\
\hline Statin medication, $n(\%)$ & $3(7.7)$ & $4(13.8)$ & $28(54.9)^{*}$ \\
\hline RAS-inhibitor medication, $n(\%)$ & $6(15.4)$ & $3(10.3)$ & $18(35.3)^{*}$ \\
\hline \multicolumn{4}{|l|}{ Nerve conduction study } \\
\hline Conduction velocity peroneal nerve $(\mathrm{m} / \mathrm{s})$ & $50.0(45.0-52.0)$ & $48.0(43.0-50.0)^{*}$ & $45.0(41.0-50.0)^{*}$ \\
\hline Conduction velocity sural nerve (m/s) & $49.0(44.0-53.0)$ & $47.0(43.0-51.5)$ & $45.0(42.0-49.8)^{*}$ \\
\hline Amplitude sural nerve $(\mu \mathrm{V})$ & $10.0(6.0-14.5)$ & $9.5(5.3-15.0)$ & $8.0(3.3-14.0)$ \\
\hline Composite $z$ score leg & $0.009 \pm 0.781$ & $-0.298 \pm 0.881$ & $-0.531 \pm 0.864^{*}$ \\
\hline NDS & $3.0(1.0-6.0)$ & $4.0(1.3-6.0)$ & $5.5(2.0-12.0)^{* \dagger}$ \\
\hline \multicolumn{4}{|l|}{ Score tertiles, $n(\%)$} \\
\hline First tertile $(0-2)$ & $17(43.6)$ & $11(39.3)$ & $13(26.0)$ \\
\hline Second tertile (3-6) & $13(33.3)$ & $12(42.9)$ & $16(32.0)$ \\
\hline Third tertile $(\geq 7)$ & $9(23.1)$ & $5(17.9)$ & $21(42.0)^{* \dagger}$ \\
\hline
\end{tabular}


score, reflecting the nerve function in the leg, was significantly lower in the diabetes group than in controls (Table 1).

sHSP27 and nerve conduction

Individuals in the highest tertile of composite $z$ score leg had significantly higher sHSP27 levels (geometric mean sHSP27 $435 \mathrm{pg} / \mathrm{ml}, 95 \%$ CI 339, 559) than individuals in the lowest tertile (geometric mean sHSP27 $229 \mathrm{pg} / \mathrm{ml}, 95 \%$ CI $159,329, p=0.027)$.

\section{sHSP27 and NDS}

Members of the diabetes group had significantly higher NDS than those of the control group (Table 1). In line with the electrophysiological findings, individuals with few neuropathic signs (i.e. lowest tertile score; $n=41$ ) had significantly higher sHSP27 levels (geometric mean sHSP27 $401 \mathrm{pg} / \mathrm{ml}, 95 \%$ CI 310, 520) than individuals with more signs (i.e. highest tertile score; $n=35$ ) (geometric mean sHSP27 $192 \mathrm{pg} / \mathrm{ml}, 95 \%$ CI 128 , $288, p=0.007)$.
sHSP27, nerve conduction and NDS

Individuals with good nerve function and few neuropathic signs, i.e. those in the highest tertile of composite $z$ score leg and lowest tertile of NDS, were compared with individuals with poorer nerve function and many neuropathic signs, i.e. those in the lowest tertile of composite $z$ score leg and in the highest tertile of NDS. Individuals with the best function had significantly higher sHSP27 levels (geometric mean sHSP27 $443 \mathrm{pg} / \mathrm{ml}, 95 \%$ CI 338, 580 ) than individuals with poor function (geometric mean sHSP27 $207 \mathrm{pg} / \mathrm{ml}, 95 \%$ CI 126, 337, $p=0.048$ ).

Associations with composite $z$ score leg and sHSP27

Univariate linear regression analysis revealed that $\mathrm{HbA}_{1 \mathrm{c}}$ was negatively associated with $\operatorname{sHSP} 27(\beta=-0.279, p=0.002)$. Adjusting for CVD did not attenuate the association between $\mathrm{HbA}_{1 \mathrm{c}}$ and sHSP27 $(\beta=-0.256, p=0.005)$. However, after adjustment for diabetes status the association was attenuated $(\beta=-0.132, p=0.33)$. Univariate multinomial logistic regression analyses for both composite $z$ score leg and sHSP27 tertiles are shown in Table 2. Variables that were significant

Table 2 Univariate multinomial logistic regression analysis of composite $z$ score tertiles and sHSP27 tertiles

\begin{tabular}{|c|c|c|c|c|c|c|c|c|}
\hline \multirow[t]{3}{*}{ Variable } & \multicolumn{4}{|c|}{ Composite $z$ score leg ${ }^{\mathrm{a}}$} & \multicolumn{4}{|l|}{$\mathrm{sHSP} 27^{\mathrm{b}}$} \\
\hline & \multicolumn{2}{|l|}{ Second tertile } & \multicolumn{2}{|l|}{ Third tertile } & \multicolumn{2}{|l|}{ Second tertile } & \multicolumn{2}{|l|}{ Third tertile } \\
\hline & OR $(95 \% \mathrm{CI})$ & $p$ value & OR $(95 \% \mathrm{CI})$ & $p$ value & OR $(95 \% \mathrm{CI})$ & $p$ value & OR $(95 \% \mathrm{CI})$ & $p$ value \\
\hline Age (years) & $1.44(0.90,2.29)$ & 0.13 & $1.13(0.73,1.73)$ & 0.59 & $1.30(0.84,2.02)$ & 0.24 & $1.27(0.82,1.98)$ & 0.28 \\
\hline Sex (male vs female) & $2.34(0.87,6.29)$ & 0.09 & $10.0(3.47,28.9)^{*}$ & $<0.001$ & $0.70(0.29,1.71)$ & 0.44 & $1.11(0.46,2.69)$ & 0.82 \\
\hline Diabetes status & $0.53(0.21,1.32)$ & 0.17 & $0.27(0.10,0.71)^{*}$ & 0.01 & $0.57(0.23,1.39)$ & 0.22 & $0.30(0.12,0.78)^{*}$ & 0.01 \\
\hline CVD status & $0.38(0.09,1.60)$ & 0.19 & $0.54(0.14,2.02)$ & 0.36 & $0.68(0.21,2.19)$ & 0.52 & $0.32(0.08,1.32)$ & 0.12 \\
\hline Weight (kg) & $0.97(0.94,0.99)^{*}$ & 0.05 & $0.94(0.91,0.97)^{*}$ & $<0.001$ & $1.00(0.98,1.02)$ & 0.94 & $1.01(0.98,1.03)$ & 0.67 \\
\hline Height (m) & $0.94(0.89,0.99)^{*}$ & 0.02 & $0.84(0.79,0.90)^{*}$ & $<0.001$ & $1.02(0.98,1.07)$ & 0.33 & $1.01(0.96,1.05)$ & 0.82 \\
\hline BMI $\left(\mathrm{kg} / \mathrm{m}^{2}\right)$ & $0.95(0.86,1.04)$ & 0.27 & $0.94(0.85,1.03)$ & 0.18 & $0.96(0.87,1.05)$ & 0.36 & $1.02(0.93,1.12)$ & 0.67 \\
\hline $\mathrm{HbA}_{1 \mathrm{c}}(\%)$ & $0.68(0.47,0.97)^{*}$ & 0.04 & $0.43(0.26,0.71)^{*}$ & 0.001 & $0.80(0.58,1.11)$ & 0.18 & $0.65(0.44,0.95)^{*}$ & 0.03 \\
\hline $\mathrm{HbA}_{1 \mathrm{c}}(\mathrm{mmol} / \mathrm{mol})$ & $0.97(0.93,0.99)^{*}$ & 0.04 & $0.93(0.88,0.97)^{*}$ & 0.001 & $0.98(0.95,1.01)$ & 0.18 & $0.96(0.93,0.99)^{*}$ & 0.03 \\
\hline $\begin{array}{l}\text { Systolic blood pressure } \\
(\mathrm{mmHg})\end{array}$ & $0.99(0.96,1.02)$ & 0.45 & $1.00(0.97,1.03)$ & 0.94 & $1.00(0.97,1.03)$ & 0.96 & $1.01(0.98,1.04)$ & 0.50 \\
\hline $\begin{array}{l}\text { Diastolic blood pressure } \\
(\mathrm{mmHg})\end{array}$ & $0.97(0.93,1.04)$ & 0.61 & $0.96(0.91,1.02)$ & 0.18 & $0.97(0.92,1.03)$ & 0.31 & $1.01(0.96,1.07)$ & 0.69 \\
\hline Creatinine $(\mu \mathrm{mol} / \mathrm{l})$ & $1.00(0.98,1.03)$ & 0.81 & $1.00(0.98,1.03)$ & 0.73 & $1.03(0.99,1.05)$ & 0.08 & $1.01(0.98,1.04)$ & 0.49 \\
\hline hsCRP (mg/l) & $2.00(0.72,5.58)$ & 0.19 & $1.30(0.46,3.68)$ & 0.63 & $1.37(0.48,3.90)$ & 0.56 & $2.71(0.95,7.72)$ & 0.06 \\
\hline $\begin{array}{l}\text { Medication with RAS } \\
\text { inhibitor }\end{array}$ & $1.00(0.35,2.88)$ & 0.99 & $0.62(0.20,1.97)$ & 0.42 & $0.97(0.34,2.77)$ & 0.95 & $0.86(0.29,2.52)$ & 0.78 \\
\hline Medication with statins & $0.77(0.29,2.09)$ & 0.61 & $0.70(0.25,1.92)$ & 0.49 & $1.19(0.48,2.96)$ & 0.71 & $0.26(0.08,0.83)^{*}$ & 0.02 \\
\hline sHSP27 (pg/ml) & $1.12(0.76,1.65)$ & 0.56 & $1.79(1.12,2.87)^{*}$ & 0.02 & - & - & - & - \\
\hline Composite $z$ score leg & - & - & - & - & $1.67(0.96,2.90)$ & 0.07 & $2.18(1.24,3.85)^{*}$ & 0.01 \\
\hline
\end{tabular}

${ }^{\mathrm{a}}$ Reference category is the first tertile of composite $z$ score leg; ${ }^{\mathrm{b}}$ reference category is the first tertile of sHSP27

$* p<0.05$ 
in the univariate multinomial logistic regression analyses, in addition to age and sex, were used in the adjusted multinomial logistic regression models. As $\mathrm{HbA}_{1 \mathrm{c}}$ and diabetes status were highly correlated to each other $(r=0.79)$, we chose to include only $\mathrm{HbA}_{1 \mathrm{c}}$ in further multivariate analyses as we perceive $\mathrm{HbA}_{1 \mathrm{c}}$ to be the possible biological variable affecting the nerve function. Using tertiles of composite $z$ score leg as the dependent variable revealed that increasing sHSP27 levels were significantly associated with the highest tertile of composite $z$ score leg, after adjustment for age, sex, height and weight, and was not attenuated by inclusion of $\mathrm{HbA}_{1 \mathrm{c}}$ (Table 3).

Using tertiles of sHSP27 as the dependent variable revealed that increasing composite $z$ score leg, i.e. better nerve function, was associated with high sHSP27 levels after adjustment for statin medication, age and sex; this association was not attenuated after adjustment for $\mathrm{HbA}_{1 \mathrm{c}}$ (Table 3).

\section{Discussion}

In this exploratory cross-sectional study we observed, counter to our hypothesis, that high levels of sHSP27 were associated with better nerve function than in those with reduced nerve function. In addition, individuals with few neuropathic signs, based on the NDS, had higher sHSP27 levels than those with many neuropathic signs.

Type 1 and type 2 diabetes mellitus

Our results are in contrast to the study by Gruden et al. [11], who found an association between high levels of sHSP27 and neuropathy in patients with type 1 diabetes, using the same ELISA kit as in our study for measuring sHSP27. In order to explain the differing results one could speculate that type 1 diabetes, which is an autoimmune disease, may have a different HSP27 regulation compared with individuals with type 2 diabetes and IGT. Anti-HSP27 autoantibodies have been observed to damage nerve cells by inducing neuronal apoptosis [18]. However, it has been shown that anti-HSP27 antibody levels were not associated with the presence of neuropathy in individuals with type 1 diabetes [19]. In addition, the association between sHSP27 levels and nerve function could be dependent on the methods of defining neuropathy and nerve function. This may partially explain our divergent results to the study by Gruden et al. [11], where the severity of neuropathy was assessed relatively crudely by symptoms, loss of ankle reflexes and vibratory perception threshold. Such a method possibly identified patients with significantly worse neuropathy than in our study, where nerve conduction was used for assessment of nerve function.

\section{IGT, $\mathrm{HbA}_{1 \mathrm{c}}$ and sHSP27}

We found a significant negative association between $\mathrm{HbA}_{1 \mathrm{c}}$ and sHSP27, and observed a rising $\mathrm{HbA}_{1 \mathrm{c}}$ throughout the NGT, IGT and type 2 diabetes groups. However, the sHSP27 levels were higher in the IGT group than both the NGT and type 2 diabetes groups. We have no obvious explanation for this observation but we speculate that it might have to do with the heterogeneity of IGT; a small proportion go on to develop diabetes, whereas others continue to have IGT for many years and some even revert to NGT. As this is a cross-sectional study, we have no control of how long the different individuals have been in

Table 3 Multinomial logistic regression models of composite $z$ score leg tertiles or sHSP27 tertiles as the dependent variable

\begin{tabular}{|c|c|c|c|}
\hline Variable & First tertile & $\begin{array}{l}\text { Second tertile } \\
\text { OR }(95 \% \mathrm{CI})\end{array}$ & $\begin{array}{l}\text { Third tertile } \\
\text { OR }(95 \% \mathrm{CI})\end{array}$ \\
\hline \multicolumn{4}{|l|}{ Composite $z$ score leg ${ }^{\mathrm{a}}$} \\
\hline sHSP27 & 1 & $1.12(0.76,1.65)$ & $1.79(1.12,2.87)^{*}$ \\
\hline Model 1 & 1 & $1.31(0.86,2.00)$ & $2.52(1.38,4.60)^{*}$ \\
\hline Model 2 & 1 & $1.12(0.72,1.75)$ & $2.11(1.10,4.18)^{*}$ \\
\hline \multicolumn{4}{|l|}{$\mathrm{HSP} 27^{\mathrm{b}}$} \\
\hline Composite $z$ score leg & 1 & $1.67(0.96,2.90)$ & $2.18(1.24,3.85)^{*}$ \\
\hline Model 3 & 1 & $2.00(1.07,3.72)^{*}$ & $2.59(1.33,5.04)^{*}$ \\
\hline Model 4 & 1 & $1.83(0.96,3.47)$ & $2.51(1.25,5.05)^{*}$ \\
\hline
\end{tabular}

Model 1: adjustment for age, sex, height and weight; Model 2: adjustment for age, sex, height, weight and $\mathrm{HbA}_{1 \mathrm{c}}$; Model 3: adjustment for age, sex and statin medication; Model 4: adjustment for age, sex, statin medication and $\mathrm{HbA}_{1 \mathrm{c}}$

${ }^{a} 1$ st composite $z$ score leg tertile is the reference group, OR $(95 \% \mathrm{CI})$ values are for levels of sHSP27 by composite $z$ score leg tertiles

${ }^{\mathrm{b}} 1$ st sHSP27 tertile is the reference group, OR $(95 \% \mathrm{CI})$ values are for composite $z$ score leg values by sHSP27 tertiles

${ }^{*} p<0.05$ vs first tertile 
the IGT state, and the time in a hyperglycaemic state might play an important role for HSP27 levels as well as for nerve function. However, we perceive the glucose level, i.e. $\mathrm{HbA}_{1 \mathrm{c}}$, to be the biological factor affecting the nerves $[20,21]$. Thus, we interpret our findings as hyperglycaemia having a negative effect on nerves; an effect that is mirrored by lower levels of HSP27.

\section{Co-morbidity and sHSP27}

Co-morbid states, such as CVD, might affect sHSP27 levels. In our study, we found that SHSP27 levels tended to be higher in participants with CVD than in those without CVD. Burut et al. [22] observed that sHSP27 levels were significantly increased in individuals with glucose intolerance (IGT and type 2 diabetes) and coexisting CVD compared with individuals with glucose intolerance but without CVD. However, Martin-Ventura et al. have shown that circulating levels of HSP27 were significantly decreased in atherosclerotic individuals compared with healthy controls [8]. They proposed that circulating HSP27 can be degraded by enzymes from atherosclerotic plaques [23]. Thus, comorbid states such as CVD should be considered when studying sHSP27 levels in humans.

\section{HSP27 and medication}

It has been shown that statins (HMG-CoA reductase inhibitors) may increase the levels of HSP27 in neural tissue [24] and that HSP27 is affected by pathways related to the RAS [25]. In our study the patients with type 2 diabetes had a greater proportion of individuals on statin and RAS inhibitor therapy compared with controls. If HSP27 level can be modulated by pharmacological induction, this effect should be accounted for as it could possibly confound the interpretation of data. However, in our study statin or RAS inhibitor therapy was not a factor that significantly affected the association between sHSP27 levels and nerve function.

\section{Neuronal aspects of HSP27}

Induction of HSP27 has been observed in Schwann cells and in the regenerating axons after nerve injury [26]. In addition, HSP27 is also constitutively produced in sensory and motor neurons, as well as in the surrounding satellite cells [27]. It has also been reported that endothelial cells constitutively produce HSP27 in the blood [28]. Whether upregulation of HSP27 seen in such animal studies $[1,2$, 29] holds true for humans is uncertain, and the amount of overproduced HSP27 from various neuronal and nonneuronal cells needed for HSP27 to be measurable in the bloodstream is unknown. However, we observed higher sHSP27 levels in individuals with better nerve function, indicative of a potential neuroprotective function of HSP27, which is in accordance with the neuroprotective effects of HSP27 upregulation that have been proposed based on animal studies $[1,2,29]$. HSP27 may have a rather dynamic role in neuroprotection and recognising the mechanisms involved in the regulation of HSP27 in humans may thus provide important development in understanding neuropathies and nerve function.

\section{Limitations and strengths}

The limitations in our study include the relatively small group sizes, which might reduce the power, and the cross-sectional design of our study does not enable us to assess causal and temporal relationships. The strength of our study is that all individuals were recruited consecutively from a populationbased sample and were of the same age. In addition, we used a strict definition of IGT based on two OGTT.

In conclusion, high levels of sHSP27 were associated with improved nerve function and fewer neuropathic signs indicative of a neuroprotective role. SHSP27 levels could be considered for identifying and following the development of nerve dysfunction.

Acknowledgements We are indebted to the late G. Sundqvist, University Hospital Malmö, Lund University, Malmö, Sweden, who was one of the initiators of the study. We are also grateful to R. Libelius and E. Nordh, Neurophysiology, Umeå, Sweden, for examining the neurophysiological tests and for invaluable comments. The study was funded by the County Council of Västerbotten, Sweden.

Contribution statement KP wrote the manuscript, analysed and interpreted data. LBD contributed to the discussion and reviewed/edited the manuscript and was involved in the analysis and interpretation of data. $\mathrm{KB}$ measured hsCRP, contributed to the discussion and reviewed/edited the manuscript and was involved in the analysis and interpretation of data. OR was one of the designers of the study, contributed to the discussion, analysed data and reviewed/edited the manuscript. All authors approved the final version to be published.

Duality of interest The authors declare that there is no duality of interest associated with this manuscript.

\section{References}

1. Benn S, Perrelet D, Kato A et al (2002) Hsp27 upregulation and phosphorylation is required for injured sensory and motor neuron survival. Neuron 36:45-56

2. Dodge M, Wang J, Guy C, Rankin S, Rahimtula M, Mearow K (2006) Stress-induced heat shock protein 27 expression and its role in dorsal root ganglion neuronal survival. Brain Res 1068:34-48

3. Evgrafov O, Mersiyanova I, Irobi J et al (2004) Mutant small heatshock protein 27 causes axonal Charcot-Marie-Tooth disease and distal hereditary motor neuropathy. Nat Genet 36:602-606

4. Zochodne D, Verge V, Cheng C, Sun H, Johnston J (2001) Does diabetes target ganglion neurones? Progressive sensory neurone 
involvement in long-term experimental diabetes. Brain 124:23192334

5. Dunlop M, Muggli E (2000) Small heat shock protein alteration provides a mechanism to reduce mesangial cell contractility in diabetes and oxidative stress. Kidney Int 57:464-475

6. Joussen A, Huang S, Poulaki V et al (2001) In vivo retinal gene expression in early diabetes. Invest Ophthalmol Vis Sci 42:3047-3057

7. Park H, Park E, Bae S et al (2006) Expression of heat shock protein 27 in human atherosclerotic plaques and increased plasma level of heat shock protein 27 in patients with acute coronary syndrome. Circulation 114:886-893

8. Martin-Ventura J, Duran M, Blanco-Colio L et al (2004) Identification by a differential proteomic approach of heat shock protein 27 as a potential marker of atherosclerosis. Circulation 110:2216-2219

9. Williams KL, Rahimtula M, Mearow KM (2005) Hsp27 and axonal growth in adult sensory neurons in vitro. BMC Neurosci 6:24

10. Wagstaff MJ, Collaço-Moraes Y, Smith J, de Belleroche JS, Coffin RS, Latchman DS (1999) Protection of neuronal cells from apoptosis by Hsp27 delivered with a herpes simplex virus-based vector. J Biol Chem 274:5061-5069

11. Gruden G, Bruno G, Chaturvedi N et al (2008) Serum heat shock protein 27 and diabetes complications in the EURODIAB prospective complications study: a novel circulating marker for diabetic neuropathy. Diabetes 57:1966-1970

12. Norberg M, Wall S, Boman K, Weinehall L (2010) The Västerbotten Intervention Programme: background, design and implications. Glob Health Action 3

13. World Health Organization (1999) Definition, diagnosis, and classification of diabetes mellitus and its complications. World Health Organization, Geneva

14. Dyck PJ, Litchy WJ, Daube JR et al (2003) Individual attributes versus composite scores of nerve conduction abnormality: sensitivity, reproducibility, and concordance with impairment. Muscle Nerve 27:202-210

15. Thrainsdottir S, Malik R, Dahlin L et al (2003) Endoneurial capillary abnormalities presage deterioration of glucose tolerance and accompany peripheral neuropathy in man. Diabetes 52:2615-2622

16. Dyck P (1988) Detection, characterization, and staging of polyneuropathy: assessed in diabetics. Muscle Nerve 11:21-32
17. Thrainsdottir S, Malik R, Rosén I et al (2009) Sural nerve biopsy may predict future nerve dysfunction. Acta Neurol Scand 120:38-46

18. Tezel G, Wax M (2000) The mechanisms of hsp27 antibody-mediated apoptosis in retinal neuronal cells. J Neurosci 20:3552-3562

19. Burt D, Bruno G, Chaturvedi N et al (2009) Anti-heat shock protein 27 antibody levels and diabetes complications in the EURODIAB study. Diabetes Care 32:1269-1271

20. Srinivasan S, Stevens M, Wiley JW et al (2000) Diabetic peripheral neuropathy: evidence for apoptosis and associated mitochondrial dysfunction. Diabetes 49:1932-1938

21. Russell JW, Golovoy D, Vincent AM et al (2002) High glucoseinduced oxidative stress and mitochondrial dysfunction in neurons. FASEB J 16:1738-1748

22. Burut D, Borai A, Livingstone C, Ferns G (2010) Serum heat shock protein 27 antigen and antibody levels appear to be related to the macrovascular complications associated with insulin resistance: a pilot study. Cell Stress Chaperones 15:379-386

23. Martin-Ventura J, Nicolas V, Houard X et al (2006) Biological significance of decreased HSP27 in human atherosclerosis. Arterioscler Thromb Vasc Biol 26:1337-1343

24. Schmeer C, Gámez A, Tausch S, Witte OW, Isenmann S (2008) Statins modulate heat shock protein expression and enhance retinal ganglion cell survival after transient retinal ischemia/ reperfusion in vivo. Invest Ophthalmol Vis Sci 49:4971-4981

25. Meier M, King GL, Clermont A, Perez A, Hayashi M, Feener EP (2001) Angiotensin AT(1) receptor stimulates heat shock protein 27 phosphorylation in vitro and in vivo. Hypertension 38:12601265

26. Hirata K, He J, Hirakawa Y, Liu W, Wang S, Kawabuchi M (2003) HSP27 is markedly induced in Schwann cell columns and associated regenerating axons. Glia 42:1-11

27. Yamamoto M, Fan L, Wakayama T, Amano O, Iseki S (2001) Constitutive expression of the $27-\mathrm{kDa}$ heat-shock protein in neurons and satellite cells in the peripheral nervous system of the rat. Anat Rec 262:213-220

28. Portig I, Pankuweit S, Lottspeich F, Maisch B (1996) Identification of stress proteins in endothelial cells. Electrophoresis 17:803-808

29. Lewis S, Mannion R, White F et al (1999) A role for HSP27 in sensory neuron survival. J Neurosci 19:8945-8953 